\title{
Attempted synthesis of casbene by intramolecular cyclopropanation
}

\author{
Michael P. Doyle* and Ming Yan \\ Department of Chemistry, University of Arizona, Tucson, Arizona 85721 U.S.A. \\ E-mail:mdoyle@u.arizona.edu
}

\section{This paper is dedicated to Al Padwa on the occasion of his $65^{\text {th }}$ birthday in recognition of his outstanding contributions to organic chemistry \\ (received 19 Jul 02; accepted 06 Nov 02; published on the web 14 Nov 02)}

\begin{abstract}
The antifungal diterpene casbene has been prepared in low yield by intramolecular cyclopropanation of the vinyldiazomethane reactant formed from geranylgeraniol. Careful analysis of the reaction mixture revealed relatively unselective addition catalyzed by dirhodium(II) and copper(I) catalysts.
\end{abstract}

Keywords: Dirhodium(II) catalysis, vinyldiazomethane, copper(I) catalysis, diterpene, macrocyclization

\section{Introduction}

In 1982 T. Takahashi and coworkers at the University of Tokyo reported the synthesis of racemic casbene by intramolecular cyclopropanation of a vinyldiazomethane formed from all-trans geranylgeraniol (Scheme 1). ${ }^{1}$ Casbene is an anti-fungal diterpene from cell-free extracts of castor bean $^{2}$ and is implicated in the biosynthesis of several diterpenes. ${ }^{3}$

Takahashi reported up to a $14 \%$ yield of casbene when the vinyldiazomethane intermediate was treated with two molar equivalents of copper(I) iodide in tetrahydrofuran, and no mention was made of other cyclopropanation products. There has been no subsequent report of this cyclization process.

With our growing experience in macrocyclization chemistry employing transition-metalcatalyzed diazo decomposition ${ }^{4-6}$ we targeted the synthesis of casbene to ascertain the potential of a variety of catalysts- and especially those with chiral ligands-to effect this transformation. Rhodium(II) catalysts have shown advantages over those of copper(I) for catalytic cyclopropanation, ${ }^{7}$ but few examples have been reported of their uses beyond those with diazocarbonyl compounds. ${ }^{8}$ 


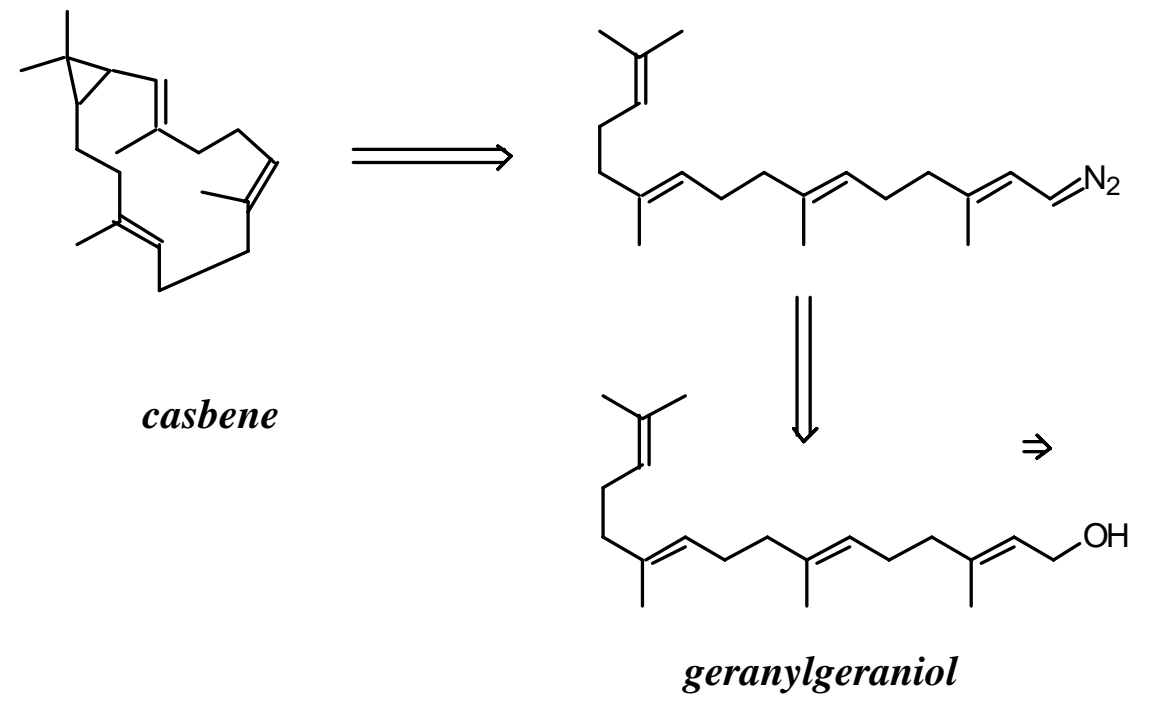

Scheme 1. Retrosynthetic analyses for casbene.

\section{Results and Discussion}

Our first task was to develop a reliable procedure for the oxidation of allylic alcohol, formation of hydrazone, and further oxidation to vinyldiazomethane (Scheme 2). The efficient conversion of vinyl-aldehydes into vinyldiazomethanes has been reported ${ }^{9}$ for model compounds, and this process was employed for the transformation in Scheme 2.
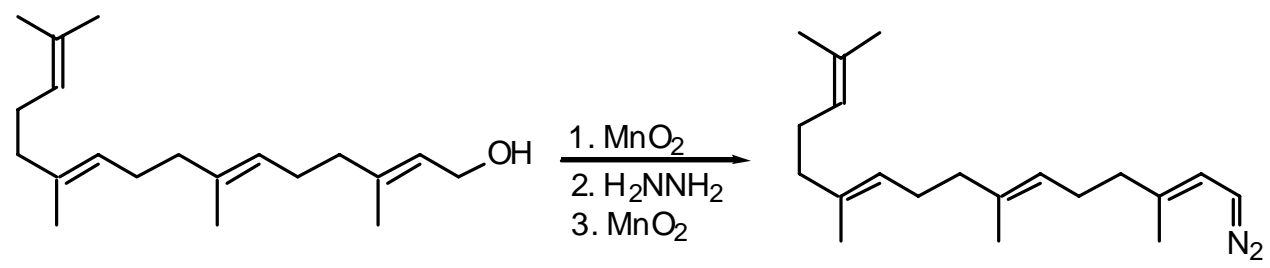

Scheme 2. Preparation of a substituted vinyldiazomethane from (geranylgeraniol) allyl alcohol.

The diazo compound formed in this way was red in solution, and used without further purification. Using $\mathrm{MnO}_{2}$ as the oxidant did cause the conversion of up to $30 \%$ of the intermediate hydrazone to geranylgeranial, but the presence of this aldehyde did not influence the selectivity for intramolecular cyclopropanation.

The importance of using the diazo compound 2 immediately, without further purification, was determined by its relative instability towards intramolecular dipolar cycloaddition (Scheme 3) - a process that is well known for vinyldiazoesters. ${ }^{10}$ This process was minimized by using the diazo compound for catalytic diazo decomposition without storage or separation of the 
geranylgeranial from 3 . The resulting pyrazole (3) could then account for more than $50 \%$ of the isolated products.

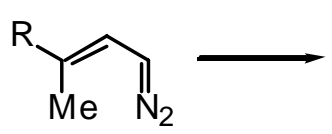

2<smiles>[R]C1(C)C=CN=N1</smiles>

3<smiles>[R]=[Ni]CC/C(C)=C\CC/C(C)=C/CCI</smiles>

Scheme 3. Intramolecular dipolar cycloaddition.

Diazo decomposition was initially investigated with $\mathrm{Rh}_{2}(\mathrm{OAc})_{4}$ as the catalyst. In this case, as expected, the major products were the pyrazole 3, geranylgeranial, and carbene dimer 4 . Only a $5 \%$ isolated yield of cyclization products was obtained, but three compounds were identified (Scheme 4), one of which was casbene (5).

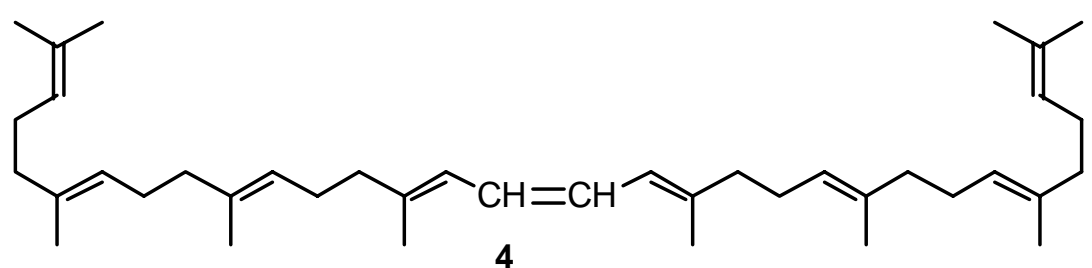

The ${ }^{1} \mathrm{H}$ NMR spectrum of casbene $(5)^{3,11}$ is characteristic in that this isomer is the only one with two methyl groups bound to an $\mathrm{sp}^{3}$-hybridized carbon and with adjacent cyclopropane ring hydrogens, one of which is at $\delta 0.5$ and has the requisite coupling constants for a designated cisgeometry.

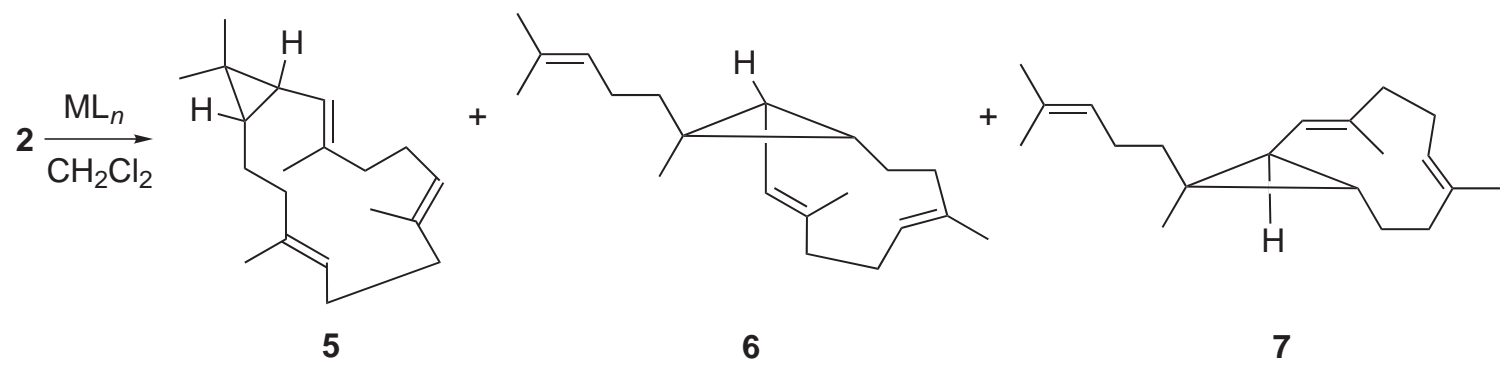

Scheme 4. Products formed by catalytic diazo decomposition of 2 , casbene.

This spectrum was sufficient to identify this product. Two other products, designated $\mathbf{6}$ and $\mathbf{7}$, were formed, the latter as a minor component and, consequently, its structural designation is more speculative. Neither $\mathbf{6}$ nor $\mathbf{7}$ has been reported previously, but their spectra are consistent with these assignments. 
Three chiral catalysts were used in attempts to prepare enantiomerically-enriched casbene. One of these was the copper-(I) bis-oxazoline complex (8) previously demonstrated to be successful for enantioselective macrocyclizations, ${ }^{4-6}$ and the other two were based on dirhodium(II), as the chiral carboxamidate (9) or carboxylate (10). ${ }^{8}$ The isolated yields of 5-7 and their distribution are given in Table 1.

Table 1. Catalytic decomposition of 2 with copper and dirhodium catalysts ${ }^{\text {a }}$

\begin{tabular}{ccc}
\hline Catalyst & $\begin{array}{c}{\text { Yield }(\%)^{\mathrm{b}} \text { of }}^{\mathbf{5 + 6}+\mathbf{7}} \\
\mathrm{Rh}_{2}(\mathrm{OAc})_{4}\end{array}$ & $\begin{array}{c}\text { Ratio }^{\mathrm{c}} \text { of } \\
\mathbf{5}: \mathbf{6}: \mathbf{7}\end{array}$ \\
\hline $\mathrm{CuPF}_{6} /$ bisoxazoline $(\mathbf{8})$ & 5.2 & $36: 63: 1$ \\
$\mathrm{Rh}_{2}(5 S-\mathrm{MEPY})_{4}(\mathbf{9})$ & 4.5 & $48: 40: 12$ \\
$\mathrm{Rh}_{2}(\mathrm{~S} \text {-TBPRO })_{4}(\mathbf{1 0})$ & 7.8 & $7: 92: 1$ \\
\hline
\end{tabular}

${ }^{a}$ Reactions were carried out in dichloromethane at $0^{\circ} \mathrm{C}$ with diazo compound: catalyst $=100: 1$. ${ }^{b}$ Isolated yield after chromatography, based on starting geranylgeranial. ${ }^{\mathrm{C}}$ Determined by GC with a SPB-5 column.

Note that $\mathrm{Rh}_{2}(5 S-\mathrm{MEPY})_{4}$ favors formation of $\mathbf{6}$, whereas $\mathrm{Rh}_{2}(S-\mathrm{TBPRO})_{4}$ favors the formation of casbene.

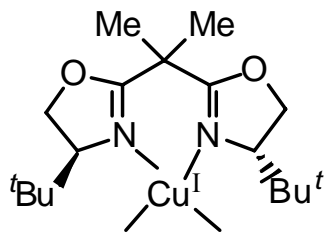

8: $\left(\mathrm{PF}_{6}^{-}\right.$salt $)$

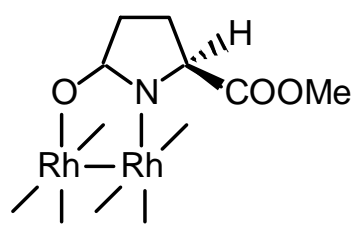

9: $\mathrm{Rh}_{2}(5 S-M E P Y)_{4}$

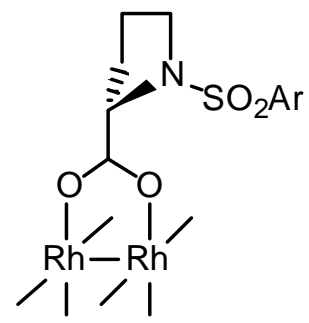

10: $\mathrm{Ar}={ }^{t} \mathrm{BuC}_{6} \mathrm{H}_{4}$

$\mathrm{Rh}_{2}(\mathrm{~S}-\mathrm{TBPRO})_{4}$

Using $\mathrm{Rh}(\mathrm{S}$-TBPRO) as the catalyst, dimer 4 was isolated in 13\% yield, and geranylgeranial was obtained in $30 \%$ yield ( $81 \%$ trans). The hydrocarbon fraction constituted a $7.8 \%$ yield, based on reactant geranylgeranial. Further purification of this sample to $85 \% \mathbf{5}+15 \% \mathbf{6}$ by column chromatography on silica impregnated with silver nitrate gave an optical rotation of $[\alpha]_{\mathrm{D}}{ }^{22}=+25.8\left(c=0.3, \mathrm{CHCl}_{3}\right)$ compared to the literature value for casbene of $+201 .^{3}$

The conclusion that we reach is that this methodology is not viable for the synthesis of casbene even though enantioselective macrocyclization does occur. Difficulties in the formation of vinyldiazo compounds, their stability once formed, and in the relatively unselective cyclopropanation, make this approach untenable for casbene or similar compounds. 


\section{Experimental Section}

Synthesis of geranylgeranial. Geranylgeraniol $(1.0 \mathrm{~g}, 3.4 \mathrm{mmol})$ was dissolved in $100 \mathrm{~mL}$ hexane in an ice-bath. To this solution active $\mathrm{MnO}_{2}$ (2.8 g, $34 \mathrm{mmol}, 10$ equiv.) was added in one portion. The reaction mixture was stirred at $0^{\circ} \mathrm{C}$ for $2 \mathrm{~h}$, filtered through a layer of Celite to remove the $\mathrm{MnO}_{2}$, and the filtrate evaporated under vacuum to give a yellow oil, which was purified by column chromatography (hexane:ethyl acetate $=12: 1$ ) to give geranylgeranial $(0.66 \mathrm{~g}, 67 \%)$ as a colorless oil whose spectra confirmed this assignment. ${ }^{1} \mathrm{H}$ NMR $(250 \mathrm{MHz}$, $\left.\mathrm{CDCl}_{3}\right): 9.95(1 \mathrm{H}, \mathrm{d}, \mathrm{J}=8 \mathrm{~Hz}), 5.88(\mathrm{~d}, \mathrm{~J}=8.1 \mathrm{~Hz}, 1 \mathrm{H}),(\mathrm{t}, \mathrm{J}=6.3 \mathrm{~Hz}, 3 \mathrm{H}), 2.25(\mathrm{~s}, 3 \mathrm{H}), 2.18$ (s, $3 \mathrm{H}), 1.9-2.15(\mathrm{~m}, 12 \mathrm{H}), 1.70(\mathrm{~s}, 3 \mathrm{H}), 1.58(\mathrm{~s}, 6 \mathrm{H})$.

Synthesis of the vinylic diazomethane 2. Geranylgeranial $(1.0 \mathrm{~g}, 3.4 \mathrm{mmol})$ and triethylamine (2.4 mL 17 mmol, 5 equiv.) were mixed in $10 \mathrm{~mL}$ anhydrous ethanol at $0^{\circ} \mathrm{C}$. To this solution was added anhydrous hydrazine, $0.52 \mathrm{~mL}$ (17 mmol, 5 equiv.), over 10 minutes, and the solution was stirred for $1 \mathrm{~h}$. The solvent and excess reagents were removed under vacuum, keeping the solution at $0^{\circ} \mathrm{C}$. A light yellow oil was obtained, which was dissolved in $10 \mathrm{~mL}$ of pre-chilled dichloromethane, and used immediately in the next step.

To a suspension of active $\mathrm{MnO}_{2}\left(2.8 \mathrm{~g}, 34 \mathrm{mmol}, 10\right.$ equiv.) and $\mathrm{Na}_{2} \mathrm{CO}_{3}$ (3.6 g, 34 mmol, 10 equiv.) in $25 \mathrm{~mL}$ dichloromethane at $0^{\circ} \mathrm{C}$ was added the preceding solution of geranylgeranyl hydrazone in dichloromethane, in one portion. The resulting mixture was stirred for $2 \mathrm{~h}$ at $0^{\circ} \mathrm{C}$. After the excess $\mathrm{MnO}_{2}$ was filtered off through a layer of Celite, a red solution was obtained and used immediately in the next step. IR (neat): $2056 \mathrm{~cm}^{-1}\left(\mathrm{C}=\mathrm{N}_{2}\right)$.

Catalytic decomposition of 3 . To a solution of the catalyst $(0.034 \mathrm{mmol}, 0.01$ equiv. $)$ in $5 \mathrm{~mL}$ dichloromethane at $0^{\circ} \mathrm{C}$ was added the solution of diazo compound 3 in dichloromethane over $0.5 \mathrm{~h}$. The resulting mixture was stirred for $1 \mathrm{~h}$ at $0^{\circ} \mathrm{C}$. The solvent was removed under vacuum and the residue purified by chromatography (hexane) to give the hydrocarbon fraction as colorless oil. Continued elution with hexane:ethyl acetate, 30:1 furnished the dimer as an oil. Eluting with hexane: ethyl acetate, 12:1, furnished geranylgeranial as colorless oil. The hydrocarbon fraction was analyzed by $\mathrm{GC}$ on an SPB-5 column (30m x $0.25 \mathrm{~mm})$. RT for compound 1, $19.01 \mathrm{~min}$, RT for compound 2, $18.47 \mathrm{~min}$, RT for compound 3 (casbene), 18.81 min. (flow rate: $1 \mathrm{~mL} / \mathrm{min}$, oven temp: $100^{\circ} \mathrm{C}$ for $2 \mathrm{~min}$, then $10^{\circ} \mathrm{C} / \mathrm{min}$ to $275^{\circ} \mathrm{C}$ ).

Casbene. ${ }^{1} \mathrm{H}$ NMR $\left(500 \mathrm{MHz}, \mathrm{CDCl}_{3}\right)$ : $0.59(\mathrm{dt}, 1 \mathrm{H}, \mathrm{J}=8.7,1.5 \mathrm{~Hz}), 0.91(\mathrm{~s}, 3 \mathrm{H}), 1.05(\mathrm{~s}, 3 \mathrm{H})$, $1.22(\mathrm{t}, 1 \mathrm{H}, \mathrm{J}=8.7 \mathrm{~Hz}), 1.54(\mathrm{~s}, 3 \mathrm{H}), 1.65(\mathrm{~s}, 3 \mathrm{H}), 1.66-2.33(\mathrm{~m}, 12 \mathrm{H}), 4.85-4.93(\mathrm{~m}, 2 \mathrm{H}), 4.97$ (t, 1H, J =6.0 Hz). MS (EI, $70 \mathrm{EV}$ ) with $\mathrm{m} / \mathrm{e}$ (rel. abund.): 272 (M, 20), 136 (50), 121 (100), 107 (65), $93(80), 67(40)$.

Compound 6. ${ }^{1} \mathrm{H}$ NMR (500 MHz, $\left.\mathrm{CDCl}_{3}\right): 0.83$ (s, 3H), $0.88(\mathrm{t}, 1 \mathrm{H}, \mathrm{J}=7.0, \mathrm{~Hz}), 1.12-1.18$ (m, $1 \mathrm{H}), 1.54(\mathrm{~s}, 6 \mathrm{H}), 1.60(\mathrm{~s}, 3 \mathrm{H}), 1.65-2.10(\mathrm{~m}, 12 \mathrm{H}), 5.07-5.14(\mathrm{~m}, 2 \mathrm{H}), 5.52-5.56(\mathrm{~m}, 1 \mathrm{H}) . \mathrm{MS}$ 
(EI, 70 EV) with m/e (rel. abund.): 272 (M, 6), 187 (25), 159 (20), 119 (92), 107 (40), 93 (60), 69 (100), 55 (25), 41 (50).

Compound 7. ${ }^{1} \mathrm{H}$ NMR (500 MHz, $\left.\mathrm{CDCl}_{3}\right): 0.81-0.89(\mathrm{~m}, 1 \mathrm{H}), 0.98(\mathrm{~d}, 1 \mathrm{H}, \mathrm{J}=7.0 \mathrm{~Hz}), 1.25$ (s, $3 \mathrm{H}), 1.53(\mathrm{~s}, 3 \mathrm{H}), 1.59(\mathrm{~s}, 6 \mathrm{H}), 1.66(\mathrm{~s}, 3 \mathrm{H}), 1.93-2.20(\mathrm{~m}, 12 \mathrm{H}), 5.05-5.13(\mathrm{~m}, 2 \mathrm{H}), 5.67-5.73$ (m, 1H). MS (EI, 70 EV) with m/e (rel. abund.): 272 (M, 12), 136 (50), 121 (100), 107 (70), 93 (90), 67 (55).

Dimer 4. ${ }^{1} \mathrm{H}$ NMR (250 MHz, $\left.\mathrm{CDCl}_{3}\right): 1.61(\mathrm{~s}, 18 \mathrm{H}), 1.70(\mathrm{~s}, 6 \mathrm{H}), 1.78(\mathrm{~s}, 6 \mathrm{H}), 1.9-2.18(\mathrm{~m}$, 24H), 5.08-5.16 (m, 6H), 5.86-5.94 (m, 2H), 5.31-5.40 (m, 2H).

\section{Acknowledgments}

Support for this research from the National Science Foundation and the National Institutes of Health (GM-46503) is gratefully acknowledged.

\section{References}

1. Toma, K.; Miyazaki, E.; Murae, T.; Takahashi, T. Chem. Lett. 1982, 863.

2. Robinson, D. R.; West, C. A. Biochemistry 1970, 9, 810.

3. McMurry, J. E.; Bosch, G. K. J. Org. Chem. 1987, 52, 4885.

4. Doyle, M. P.; Hu, W.; Chapman, B.; Marnett, A. B.; Peterson, C. S.; Vitale, J. P.; Stanley, S. A. J. Am. Chem. Soc. 2000, 122, 5718.

5. Doyle, M. P.; Hu, W. J. Org. Chem. 2000, 65, 8839.

6. Doyle, M. P.; Hu, W. Synlett 2001, 1364.

7. Davies, H. M. L.; Antoulinakis, E. G. Org. React. 2001, 57, 1.

8. Doyle, M. P.; McKervey, M. A.; Ye, T. Modern Catalytic Methods for Organic Synthesis with Diazo Compounds; Wiley \& Sons: New York, 1998.

9. Doyle, M. P.; Yan, M. J. Org. Chem. 2002, 67, 602.

10. Davies, H. M. L. Curr. Org. Chem. 1998, 2, 463.

11. Crombie, L.; Kneen, G.; Pattenden, G.; Whybrow, D. J. Chem. Soc. Perkin 1 1980, 1711. 